\section{QUALIFICATIONS OF THE SOCIAL PSYCHOLOGIST}

$\mathrm{P}$ ROF. T. H. PEAR oriticizes severely but kindly in an interesting article those who profess social psychology*. The social psychologist too frequently fails to qualify for his job by obeying the old in. junction of 'know thyself'. Also in his attitude towards his subject he is too remote from the hurlyburly of everyday life, in fact, too 'pure'. Some sciences can be pursued advantageously with little contact with, or relation to, humanity, but such is not the case with social psychology, On the other hand, he must resist the temptation to slip into the attitude of the novelist, artist or even comfort lover.

The direction of any science is determined, to an extent not usually admitted, by the inborn and acquired mental peculiarities of its leaders and by their social and economic status. Most social psychology has been produced in Great Britain by members of the middle class, and they have too often been unaware of this limiting factor. Examples of this attitude of mind have sometimes been thrown into relief during the War. For example, in discussing fuel saving, some people who had never known what it was not to be able to have a bath when they wanted one, suggested a nation-wide campaign urging people not to have more than two hot baths a week, in blind ignorance that there were numerous bethless houses.

Leaders of thought brought up in a particular environment are apt to think that certain subjects are important or trivial, popular or dull, in general, though a different culture group might hold quite different views. A social psychologist must not be 'tuned in' merely to those expressions of social life which the conventions of his social milieu regard as important. For example, the subjects of speaking and conversing are generally neglected. That such problems as standard English, the prejudices for and against certain kinds of dialect, are social, is unrealized. To delve into them would break a taboo all the stronger because in most people it is unconscious.

Therefore, before entering upon any research in social psychology the investigator should know his own social background, and the ways in which it may have given him special prejudices.

Industrial research is not a bad training in this respect. If the investigator is in one factory for a considerable time, he will have ample opportunities for finding out, incidentally to his main work, what people do think, or say they think, about the topics that are of current interest. A point of importance in this connexion is that much of what is said has to be translated or interpreted. Some students of public opinion are apt to overlook that, in Great Britain at least, to express an opinion is not synonymous with being prepared to act upon it. Much gossip and expression of opinion is of the nature of a probe to see what other people are like or think.

The somewhat humdrum task of finding out how we ourselves behave in particular circumstances, and how others do, is vitally necessary for the development of social psychology.

Prof. Pear thinks that too many men of science believe that those who are not trying to establish general laws are wasting time, even when there may - The Bocial Status of the Psychologist and its Effect upon his Work. By Prof. T. H. Pear, Sociol. Rev., 34 (Jan-April, 1942). be a serious shortage of facts in the particular subject. Even books about the human mind are often of this kind and suffer from a paucity of examples. Social psychologists have no right to neglect the observation, recording and classification of concrete data. Their scientific training would be shown in the way they used their data. In short, they must not spend their days in the study, but frequent the market-place, and know their own blind spots, mental and social.

\section{SCATTERING OF LIGHT}

$T$ HE interest which for many years now has been displayed by Indian workers on phenomena of light scattering has produced a large volume of valuable observations and many important and farreaching results. While, since 1928 , investigations have been predominantly concerned with different aspects of the Raman effect, other branches of light scattering have received attention. Many individual papers have appeared, but periodically a symposium of papers is published. These are most helpful in weaving together the various topies. The one under review* on "Fluorescence, Light Scattering, and the Raman Effect" worthily follows the traditions created by previous symposia and maintains the same high standard.

The symposium opens with two papers by P. G. N. Nayar on the absorption and scattering of light in diamonds. His earlier work had shown that both in fluorescence and absorption the entire spectrum is closely related to the $4152 \mathrm{~A}$. band. Examination of these spectra at liquid-air temperature has now revealed the existence of a considerable number of discrete lines in the spectro with frequency shifts varying from 178 to $1330 \mathrm{~cm}^{-1}$ and, further, has shown the perfect mirror-image symmetry in the shifts and in the intensities of these lines with respect to the $4152 \mathrm{~A}$. line. These data enable the author to derive the full lattice spectrum of the diamond, and the discrete character of this spectrum postulates that atomic oscillations in a simple crystalline solid are of a different nature from those of an elastic solid. Further, the derived spectrum contains practically all the known Raman and infra-red frequencies and indicates that the spectrum is richer in frequencies than had been supposed. The investigation of the ultra-violet absorption in the temperature range $85^{\circ}-300^{\circ}$ has demonstrated that the $4152 \mathrm{~A}$. line is a doublet, that between 3015 and $3447 \mathrm{~A}$. there are some twenty-five distinct lines, that below $3000 \mathrm{~A}$. there is an unresolved group, and that the influence of temperature on all lines is of the same order of magnitude. Investigation of the changes in frequency, intensity, and polarization of the 1332 $\mathrm{cm} .^{-1}$ Raman line with crystal setting and angle of scattering show that the frequency and intensity are unaltered. The depolarization factor is 1 , not 2 as obtained theoretically. One other interesting point emerges in the constancy of the intensity and frequency of the $1332 \mathrm{~cm}^{-1}$ line in diamonds exhibiting widely different fluorescence and absorption properties.

B. S. Satyanarayana discusses tho fluorescence of uranyl compounds. In the solid state the fluorescence spectrum consists of eight discrete bands having a Wave number separation of approximately $860 \mathrm{~cm}^{-1}$. The Raman spectrum of the uranyl $\mathrm{UO}_{2}++$ ion con-

*Proc. Indian Aead. Sci., A, 15, 293-416 (1942). 
sists of three displacements of 211,865 , and $909 \mathrm{~cm}^{-1}$. It is concluded from an analysis of the Raman data that the ion has a symmetrical, bent structure.

More than workers in other countries, Indian physicists have directed attention to the interesting changes in the Raman spectra of crystals on account of different crystal settings, and of the influences of the directions of the incident and scattered radiation. T. M. K. Nedungadi has extended our knowledge on this topic by an exhaustive investigation of the Raman effect in a single crystal of naphthalene. The spectrograms obtained for various settings of the crystal with respect to the directions of the incident radiation and the line of observation and with various directions of vibration in the incident and scattered radiation are reproducod. Experimental data confirm predictions of group theory that six low-frequency lattice oscillations exist in three pairs of close doublets : 38,$47 ; 72,78$; and 107 , $121 \mathrm{~cm}^{-1}$. The higher member of each pair arises from oscillations symmetrical to the elements of symmetry of the monoclinic lattice, whereas the lower members of the pairs are due to antisymmetrical oscillations. On frequency and intensity considerations these pairs of lines correspond roughly with rotational oseillations of the molecule. Theoretically, naphthalene should possess twenty-four normal modes of vibration and these have been identified. Polarization data have shown that some of the intermal oscillations, particularly 512 and $1576 \mathrm{~cm}^{-1}$, split up into symmetric and antisymmetric components; this is interpreted as showing that polariza. tion data are controlled, as are lattice oscillations, by symmetry properties.

Work continues on determination of the Raman frequencies and their intensities and polarization characteristios and on deducing the characteristic Raman frequencies of chemical groups and linkages. Contributions in this direction are made by Dr. C. S. Venkateswaran and N. S. Pandya with data on aniline, diethyl sulphide, and two binary liquid mixtures. The binary mixtures investigated-cyclohexane-aniline and iso-propyl alcohol-water-possess a critical solution temperature and, from changes in the position and intensity of five lines of the second mixture, it is concluded that at the critical solution temperature only monomerio molecules of iso-propyl alcohol exist. This is an interesting new departure in Raman spectral investigations, and shows that the directions in which the methods of Raman spectra can be applied to the investigation of chemical problems are, indeed, manifold.

The remaining papers of the symposium deal with the scattering of light in gases, in mobile and viscous liquids, in glasses, in alcohols, and in emulsions. The light scattered in a transverse horizontal direction by dilute emulsions is usually elliptically polarized, whereas the scattered light from concentrated emulsions is highly depolarized. In a large variety of liquids hypersonic velocities have been determined and compared with acoustic velocities. K. S. Bai has examined existing theories of light transversely scattered by liquids and has derived thermodynamically a general expression for the intensity.

The contents of the papers constituting the symposium will prove extremely valuable not only to all directly concerned with this field of scientific inquiry, but also to a wide circle of chemists and physicists interested in the applications of these methods to a variety of problems.

W. Rogie Angus.

\section{THE LOCUST PLAGUE}

\author{
By DR. A. D. IMMS, F.R.S.
}

$\mathrm{O}^{\mathrm{s}}$ $\mathrm{NE}$ of the oldest of all agricultural problems is that of locust invasions. References to such plagues are frequent in the texts of the ancient Egyptians, Greeks, Chinese and Hebrews-the oldest dates back to more than 2000 years B.c. These depredations are not confined to a few countries, although outbreaks regularly appear in individual lands only to devastate many distant territories. It cannot be emphasized too strongly that much of the failure to control these plagues has been due to isolationist policy adopted by those countries directly affected.

This feature was stressed by Dr. B. P. Uvarov in a lecture delivered by him before the Dominions and Colonies Section of the Royal Society of Arts on December 15. As Dr. Uvarov pointed out, history provides examples of great efforts to control locusts in Algeria, Argentina, South Africa, etc., with only temporary results simply because the problem is insoluble within the confines of a single country. He mentions the example of swarms of the desert Iocust, bred in India, that usually migrate to Persia and Arabia and their descendants proceed to spread over Egypt, Palestine and East Africa.

It is now generally agreed among investigators, and the more enlightened administrators of locust control methods, that international co-operation affords the only sure method leading to the ultimate and permanent solution of the problem. Sporadic attempts to approach some measure of international co-operation have not been lacking, but no practical effect resulted owing to failure to take scientifically planned concerted measures. In 1928 a severe outbreak of the desert locust was the moving factor in the British Government deciding to take steps that might lead to a solution of the causes of the periodical swarming of locusts and the resulting depredations. A Locust Sub-Committee of the Committee of Civil Research (later transformed into the Committee on Locust Control of the Economic Advisory Council) was formed. The actual work was undertaken by a special research unit under the supervision of Sir Guy Marshall and under the technical supervision o Dr. B. P. Uvarov. The history of this important venture and the results so far obtained were dealt with in the lecture referred to. In a few words it may be said that this purely British organization soon attracted attention in other lands.

The first International Locust Conference at Rome in 1930 requested the British organization to act as the centre of anti-locust research. Concerted investigations by parties of British, Belgian, South African, Egyptian and Indian experts have gradually led towards a fundamental understanding of the whole problem. After eight years of intensive work it has become possible to formulate a policy that aims directly at a radical solution of the difficulties. The investigations referred to have yielded abundant data showing that the periodicity of locust outbreaks is closely connected with transformation of these insects from the harmless solitary phase into the dangerous migratory, gregarious one. The transformation can happen only in certain localized areas with special conditions of climate and vegetation which differ for different locust species. It is in these outbreak areas that the first swarms are formed. The important discovery that great locust invasions 